\title{
Relationship between Death Conference Experiences and Nurses' Terminal Care
}

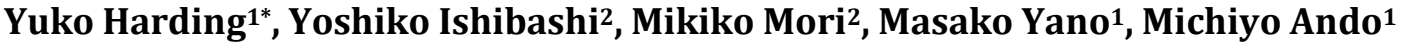 \\ ${ }^{1}$ Faculty of Nursing, St. Mary's College, Kurume, Japan \\ ${ }^{2}$ Department of Nursing, St. Mary's Hospital, Kurume, Japan \\ Email: *yukohardinaha@yahoo.co.jp
}

How to cite this paper: Harding, Y., Ishibashi, Y., Mori, M., Yano, M. and Ando, M (2020) Relationship between Death Conference Experiences and Nurses' Terminal Care. Open Journal of Nursing, 10, 381-395. https://doi.org/10.4236/ojn.2020.104026

Received: February 20, 2020

Accepted: April 11, 2020

Published: April 14, 2020

Copyright () 2020 by author(s) and Scientific Research Publishing Inc. This work is licensed under the Creative Commons Attribution-NonCommercial International License (CC BY-NC 4.0). http://creativecommons.org/licenses/by-nc/4.0/ cc) (i) (8) Open Access

\begin{abstract}
Background: The experiences of death conference (DC) are regarded as improving the quality of nurses' terminal care and developing nursing minds. Few studies in Japan clarify quantitatively how nurses' participation in DC is related to nurses' terminal care. Aim: This study aims to clarify the relationship between DC experiences and nurses' terminal care using the prepared Terminal Care Nursing Self-Assessment Sheet. Method: The study is approved by the Ethics Review Board of St. Mary's College, and the hospital where the survey was conducted. This study was an observational and cross-sectional study using an anonymous, self-completed questionnaire composed of the newly created Terminal Care Nursing Self-Assessment Sheet. Its evaluation items consist of six categories (Reflection, Cooperation, Response to patients, Response to patients' family, Specific measures for nursing, and Feelings of the nurse), and 14 questions. The questionnaires were conducted for 144 nurses in the ER, ICU, and Palliative Care Ward (Hospice Ward) in a general hospital in Japan. For analysis, JMP ver.14.2 was used to perform a Chi-square test, Wilcoxon/Mann Whitney test, univariate, and multivariate logistic regression analysis. Results: One hundred thirty-nine participants (97\%) were included in the final analysis. Forty-three nurses had DC experiences, and 96 had no experience. The median number (IQR; interquartile range) of DC experiences was 5.5 (2 - 22.5). There were significant differences in five of the above categories; however, there was no significant association in the five questions of the nurse's stress on response to patients and patients' family and specific measures for nursing regarding postmortem treatment for patients between DC experiences and Nurses' terminal care. Conclusion: DC that looks back on terminal care has significance as an opportunity to consider the way of terminal concerns and direction of future care. It is required to raise the quality of DC for focusing on reducing nurses' stress on terminal care and anxiety about postmortem treatment for patients.
\end{abstract}




\section{Keywords}

Death Conference, DC, Terminal Care, Self-Assessment, Nurses

\section{Introduction}

Nurses may be exposed to a great deal of stress, fear of death, or traumatic psychological situations that also affect their life and work when faced with patient mortality. Many nurses who care for end-of-life patients experience anxiety, fear, and fear of death [1]. And if they do not have a firm view of life and death, fear of death occurs within themselves, and nurses are said to be unable to communicate with patients to defend against terror [2].

In the emergency room, there is a tendency to be aware of lifesaving and survival of life ideas, and to avoid death. Besides difficulties involved with critically ill patients and their families, this is the result of not being aware of the point of view of care for death because of their awareness of death as a taboo. If neither the clinician nor the family has daily thoughts on death, when the end of the patient becomes unavoidable, care cannot take to prepare for the death [3]. In providing advanced medical care, nurses are developing treatment and nursing care under a common concept while gaining consensus with other occupations in team medical care. It is necessary for nurses and medical staff who care for dying patients to learn about death and to establish a view of life and death [4]. In the future, it will be necessary for healthcare professionals to share their views on life and death and to provide holistic care to patients in terminal phase.

Terminal care refers to care based on the aspect of life and death. It aids that help to relieve suffering from dying persons as much as possible and to make the transition to new worlds. Terminal care is defined as the care of terminally ill patients, such as those with terminal cancer, in which death is unavoidable, and also as the end-of-life care in emergency and intensive care, that is, when acutely ill patients treated in an intensive care unit are judged to be unlikely to be saved even after appropriate treatment is performed [5] [6] [7].

Death Conference (DC) is a place where the physicians and nurses who are facing the patient's death look back on the care of the deceased patient to improve the quality of care in the future [8] [9] [10] [11] [12]. It should also include a review of nurses' terminal care of deceased patients and a case conference of patients with medical staff in their department.

DC experience is indispensable for improving the quality of nurses' terminal care and developing nursing minds. We thought that a self-assessment sheet for nursing, including the concept of the significance of DC, is necessary to reflect on everyday terminal care, including the emergency and acute phases, and to enhance the content of DC and death education. Therefore, first of all, we conducted a literature review in previous research to clarify the significance of DC. It explained that improving the quality of DC could lead to the improvement of 
the quality of patient care and the effect of catharsis for nurses [13].

Currently, there are only a few studies in Japan that clarify quantitatively how nurses' participation in DC is related to the current state of terminal care. The background of nurses is that there are differences in the status of nurses participating in DC, gender, affiliation, years of experience, age, educational background, and experience of post-mortem treatment. Hence, it may be necessary to consider nurses' participation in DC and the current state of terminal care.

This study aims to clarify the relationship between DC experiences and the current situation of terminal care for nurses who have experienced using the prepared Terminal Care Nursing Self-Assessment Sheet.

\section{Methods}

\subsection{Participants}

Eligible participants were nurses who are considered to have experienced terminal care in a general hospital that has an ER, HCU, and Palliative Care Ward (Hospice Ward) in Japan. In all, we recruited 144 participants who work in an ER, HCU, and Palliative Care Ward and who worked in May 2018. Participants excluded from the study for the following reasons: those who were not assigned to the HCU, ER, Palliative Care Ward for more than two months.

\subsection{Procedure}

This study was an observational and cross-sectional study using an anonymous, self-completed questionnaire composed of the newly created Terminal Care Nursing Self-Assessment Sheet. This study was approved by the Ethics Review Board of St. Mary's College, and the hospital where surveys were completed. The study was conducted following the Declaration of Helsinki. We distributed consent documents with the anonymous, self-completed questionnaire before the survey to all participants through the head nurse from the nursing department and asked them to fill out the questionnaire as having their consent by answering freely. The consent form stated that there would be no disadvantage even if they did not participate in the research. The survey had a response time of 10 to 15 minutes. It was placed in an envelope, sealed, and collected by collaborators using a two-week retention method. All participants underwent an anonymous, self-completed survey composed of the Terminal Care Nursing Self-Assessment Sheet. This sheet focuses on Reflection, Cooperation, Response to patients, Response to patient' family, Specific measures for nursing, and Feelings of the nurse. The participant characteristics were gender, affiliation, clinical experience, age, academic background, number of postmortem experiences, and with or without and the number of DC experiences.

A Terminal Care Nursing Self-Assessment Sheet was created using a 5-step Likert scale of 1 to 5 for all items. In the beginning they are asked, "How often do you think about your nursing at the current terminal care and death conference, please circle the closest numbers respectively?" For this, the following 
steps were set. Here were scoring and answers for questions of all 14 items, " 1 . I never think about it, 2. I rarely think about it, 3. I sometimes think about it, 4. I often think about it, 5. I always think about it." The evaluation items consist of six categories and 14 questions. Those categories and subjects are including the concept of the significance of DC (Open Journal of Nursing, 2019, 9, pp. 527) [13] that was revealed in previous literature reviews [9] [11] [12] [14] [15] [16] [17] [18], and incorporated as a conceptual framework (Table 1). Three collaborators in previous studies reviewed the category of the significance of DC. This time, to ensure content validity, the 14 assessment items were initially considered and prepared by two co-authors of university teachers with clinical experience in terminal care as nurses. Next, we obtained advice from another co-author, a college faculty member conducting terminal care research, and two other co-authors, chief nurse managers who are in charge of the terminal care ward. The translation from Japanese to English and back translation of the 14

Table 1. Items of terminal care nursing self-assessment sheet derived from literature reviews.

\begin{tabular}{|c|c|c|c|}
\hline Category* & Significance of $\mathrm{DC}^{*}$ & $\mathrm{No}^{\dagger}$ & Items of Terminal Care Nursing Self-Assessment Sheet \\
\hline Reflection & $\begin{array}{l}\text { Review of nursing care provided by } \\
\text { self-reflection }\end{array}$ & $\mathrm{T} 1$ & I have been able to look back on the nursing I performed. \\
\hline \multirow[t]{2}{*}{ Cooperation } & Collaboration with other professions & $\mathrm{T} 2$ & $\begin{array}{l}\text { I am strengthening cooperation with other professions about } \\
\text { patient care. }\end{array}$ \\
\hline & Bond with patient and family & $\mathrm{T} 13$ & I feel a renewed bond with my patients and their family. \\
\hline \multirow{3}{*}{$\begin{array}{l}\text { Response to } \\
\text { patients }\end{array}$} & $\begin{array}{l}\text { Response to unrelieved mental and } \\
\text { physical pain in a patient }\end{array}$ & T5 & $\begin{array}{l}\text { I have stress resulting from the patient's inability to relieve } \\
\text { mental or physical pain. }\end{array}$ \\
\hline & $\begin{array}{l}\text { Involvement with patients who have a } \\
\text { gap in perceptions of the condition }\end{array}$ & T6 & $\begin{array}{l}\text { I have stress associated with patients who have a different } \\
\text { perception of their conditions. }\end{array}$ \\
\hline & $\begin{array}{l}\text { The act of responding to a patient's } \\
\text { emotional expression and questions } \\
\text { about the patient's remaining life }\end{array}$ & $\begin{array}{l}\text { T7 } \\
\text { T8 }\end{array}$ & $\begin{array}{l}\text { I have stress from patients' emotional expression. } \\
\text { I am stressed out from responding to questions from } \\
\text { patients about life expectancy. }\end{array}$ \\
\hline \multirow{3}{*}{$\begin{array}{l}\text { Response to } \\
\text { patients' family }\end{array}$} & Respect for family-to-patient wishes & T3 & $\begin{array}{l}\text { I respect the wishes of patients' family members } \\
\text { toward patients. }\end{array}$ \\
\hline & $\begin{array}{l}\text { Dealing with family members of } \\
\text { patients who seem to have } \\
\text { difficulty involved }\end{array}$ & T9 & $\begin{array}{l}\text { I am stressed out by the family of patients who are considered } \\
\text { difficult to care for. }\end{array}$ \\
\hline & $\begin{array}{l}\text { Anxiety and concern about the } \\
\text { family's treatment of patients }\end{array}$ & $\mathrm{T} 12$ & $\begin{array}{l}\text { I am anxious and worried about the treatment of patients by } \\
\text { their families. }\end{array}$ \\
\hline \multirow[t]{2}{*}{$\begin{array}{l}\text { Specific measures } \\
\text { for nursing }\end{array}$} & $\begin{array}{l}\text { Procedures for postmortem treatment } \\
\text { and technique concerns }\end{array}$ & $\mathrm{T} 10$ & $\begin{array}{l}\text { I have misgivings about procedures and skills for postmortem } \\
\text { treatment. }\end{array}$ \\
\hline & $\begin{array}{l}\text { Thoughts of nurses who support the } \\
\text { decision-making of terminal cancer } \\
\text { patients }\end{array}$ & $\mathrm{T} 4$ & $\begin{array}{l}\text { I support the decision-making of dying patients and their } \\
\text { families. }\end{array}$ \\
\hline \multirow[t]{2}{*}{ Feelings of the nurse } & $\begin{array}{l}\text { Awareness of the emotional reaction to } \\
\text { a dying patient }\end{array}$ & $\mathrm{T} 11$ & I have emotional reactions toward dying patients. \\
\hline & $\begin{array}{l}\text { Satisfaction with satisfying patients' } \\
\text { wishes }\end{array}$ & $\mathrm{T} 14$ & $\begin{array}{l}\text { I have a sense of satisfaction in fulfilling the wishes of the } \\
\text { patients, such as the patients spending time with their } \\
\text { families. }\end{array}$ \\
\hline
\end{tabular}

${ }^{\star}$ Open Journal of Nursing, 2019, 9, pp. 527 [13]; ${ }^{\dagger}$ No., question No., T, Items of terminal care nursing self-assessment sheet. 
items in the Terminal Care Nursing Self-Assessment Sheet was confirmed by two bilingual native adults in English and Japanese and a request was also made to an English proofreading company. They also verified the consistency of these 14 items with six categories and the meaning of DC. Participants' characteristics question items are first identified by collaborators and then advised by the nursing department of the institution surveyed without the use of individual identification.

\subsection{Analysis}

Data were analyzed using JMP (ver. 14.2; SAS Institute Inc., Cary, NC, U.S.). Gender, affiliation, age, academic background, and the number of postmortem experiences are expressed as observation numbers and percentages. The chi-square test was used for categorical variables. The characteristics: clinical experience and number of DC experiences were evaluated by the Mann-Whitney $\mathrm{U}$ test to investigate the difference in the groups between the nurses with (Yes group) and without (No group) participation in DC. The results presented are in the median and IQR; interquartile range. The affiliation variable is divided into HCU and others (ER and Palliative Care Ward). The academic background variable in divided into technical college, junior college, four-year university, and others (a particular course of junior college or university, five-year school, and graduate course).

The results of the median and IQR are presented as follows. In the univariate analysis for items in the Terminal Care Nursing Self-Assessment Sheet by DC experiences, which are categorized by participating in DC: Yes or No., the $P$ values from the Mann-Whitney tests are analyzed. Univariate and multivariate logistic regression analysis was used for variables in the Terminal Care Nursing Self-Assessment Sheet predicting DC experiences. In the multivariate analysis, three models are presented with the variables used for adjustment. Model 1 was adjusted for gender, affiliation (HCU, ER, Palliative Care Ward), clinical experience, age, academic background, postmortem experience. Model 2 was adjusted for gender, affiliation (HCU, others), clinical experience, age, academic background, postmortem experience. Model 3 was adjusted for gender, academic background.

$P$ values $<0.05$ were considered significant. The sample size calculation used the EPI-INFO 7.0 statistical package. A sample size of at least 132 participants of the population size of 1000 nurses included public health nurses, midwives, associate nurses defined as sufficient for an $85 \%$ incidence rate with the statistical power of $80 \%$, an acceptable margin of error of $5 \%$ and a confidence level of 95\%.

\section{Results}

\subsection{The Process of the Enrolment and Participant Characteristics}

A flow diagram summarizing the enrolment process is illustrated in Figure 1. 


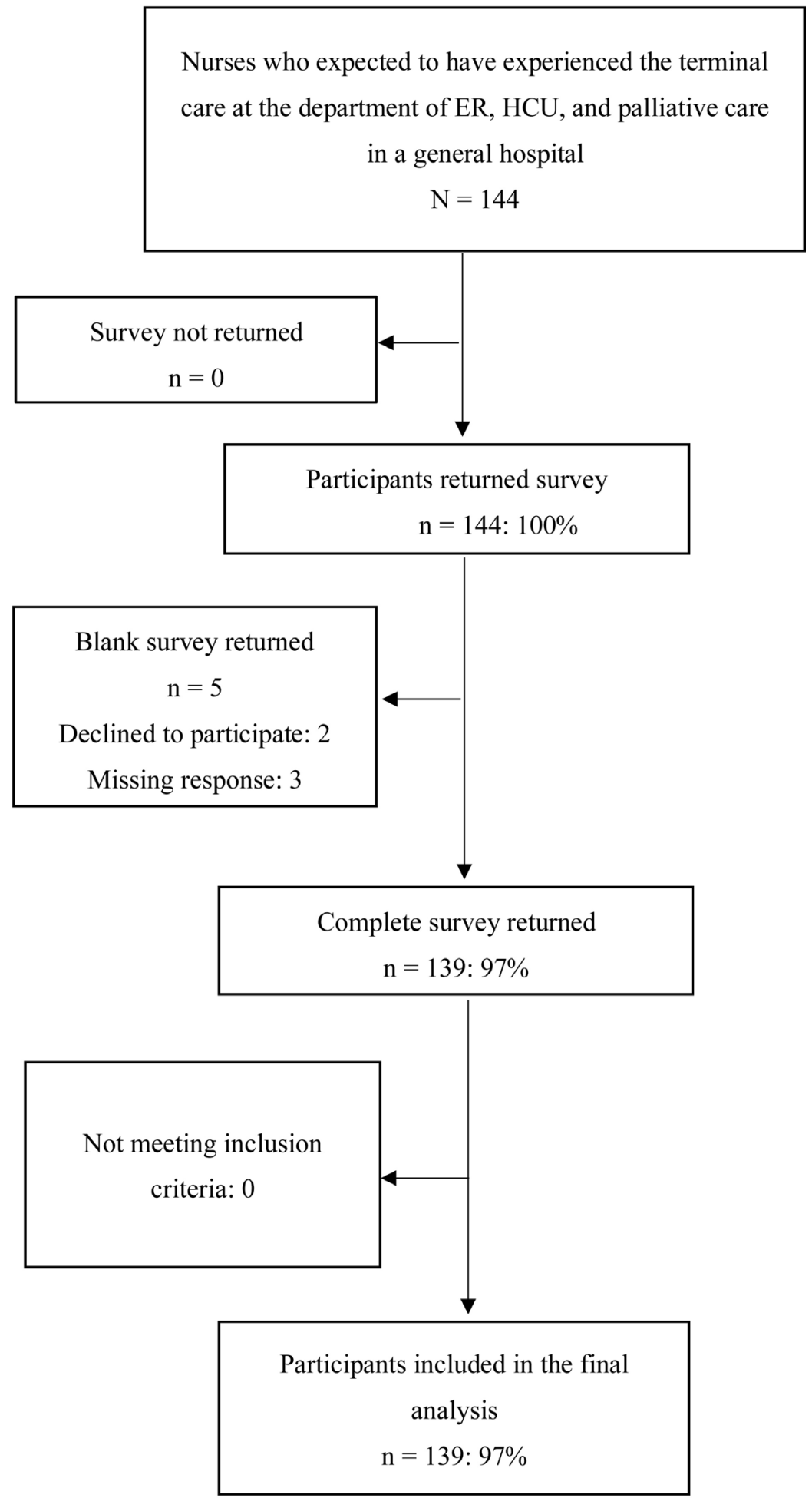

Figure 1. Flow diagram summarizing the enrollment process.

During the study period, 144 nurses are expected to have experienced terminal care at the department of ER, HCU, and Palliative Care Ward in a general hospital. Responses were received from all 144 participants who distributed the survey. In the final analysis, 139 participants (97\%) are included. 
Characteristics of the study participants are listed in Table 2. Each eligible nurse in the study group is classified according to DC experiences, Yes group $(31 \%, n=43)$, or No group $(69 \%, n=96)$, and comparisons were made between the groups. Gender distribution was as follows: in the Yes group, there were 3 men and 40 women participants; in the No group, there were 17 men and 79 women participants. The affiliation of nurses was $68.4 \%$ for HCU, $20.9 \%$ for ER, and $10.8 \%$ for Palliative Care Ward. Seventy-two (75\%) of 96 nurses in the No group of DC experiences belong to $\mathrm{HCU}$, as were $53.5 \%$ in the Yes group. The median (Interquartile range, IQR) clinical experience of all participants was 7 (3 14.8) years. The median (interquartile range) clinical experience in the Yes group and the No group were $11(5.5-20)$ years and $5(3-11)$ years, respectively.

Table 2. Participant characteristics.

\begin{tabular}{|c|c|c|c|c|}
\hline & \multirow{2}{*}{$\begin{array}{l}\text { All nurses } \\
\mathrm{N}=139\end{array}$} & \multicolumn{2}{|c|}{ DC experiences } & \multirow{2}{*}{$\begin{array}{c}P \\
\text { value }\end{array}$} \\
\hline Characteristics & & $\begin{array}{c}\text { Yes } \\
\mathrm{n}=43\end{array}$ & $\begin{array}{c}\text { No } \\
\mathrm{n}=96\end{array}$ & \\
\hline Gender, no. $(\%)^{*}$ & & & & 0.08 \\
\hline Men & $20(14.4)$ & $3(7.0)$ & $17(17.7)$ & - \\
\hline Women & $119(85.6)$ & $40(93.0)$ & $79(82.3)$ & - \\
\hline Affiliation, no. $(\%)^{*}$ & & & & $<0.01$ \\
\hline $\mathrm{HCU}$ & $95(68.4)$ & $23(53.5)$ & $72(75.0)$ & 0.01 \\
\hline Others $^{\dagger}$ ER & $29(20.9)$ & $5(11.6)$ & $24(25.0)$ & 0.06 \\
\hline Palliative Care Ward & $15(10.8)$ & $15(34.9)$ & $0(0)$ & $<0.01$ \\
\hline Clinical experience, Median (IQR), $\mathrm{y}^{\ddagger}$ & $7(3-14.8)$ & $11(5.5-20)$ & $5(3-11)$ & 0.01 \\
\hline Age group, no. $(\%)^{*}$ & & & & 0.09 \\
\hline$<30$ & $66(47.5)$ & $15(34.9)$ & $51(53.1)$ & 0.06 \\
\hline $30-39$ & $44(31.7)$ & $15(34.9)$ & $29(30.2)$ & 0.58 \\
\hline$\geq 40$ & $29(20.9)$ & $13(30.2)$ & $16(16.7)$ & 0.07 \\
\hline Academic background, no. $(\%)^{\star}$ & & & & 0.10 \\
\hline Technical college & $70(50.4)$ & $18(41.9)$ & $52(54.2)$ & 0.18 \\
\hline Junior college & $14(10.1)$ & $8(18.6)$ & $6(6.3)$ & 0.03 \\
\hline Four-year university & $31(22.3)$ & $8(18.6)$ & $23(24.0)$ & 0.48 \\
\hline Others $^{\S}$ & $24(17.3)$ & $9(20.9)$ & $15(15.6)$ & 0.44 \\
\hline The number of postmortem experiences, no. $(\%)^{*}$ & & & & 0.01 \\
\hline 0 & 0 & 0 & 0 & - \\
\hline $1-9$ & $41(29.5)$ & $10(23.3)$ & $31(32.3)$ & 0.32 \\
\hline $10-19$ & $29(20.9)$ & $4(9.3)$ & $25(26.0)$ & 0.02 \\
\hline$\geq 20$ & $69(49.6)$ & $29(67.4)$ & $40(41.7)$ & $<0.01$ \\
\hline Number of DC experiences, Median (IQR), $\mathrm{y}^{\ddagger}$ & $5.5(2-22.5)$ & & & - \\
\hline
\end{tabular}

$\mathrm{IQR}$, inter quartile range. DC, Death Conference. ${ }^{\star} P$ values are from $\mathrm{X}^{2}$ test analyzed on nonparametric comparisons between the nurses with (Yes) and without (No) participating in DC. ${ }^{\dagger}$ Others included ER and Palliative Care Ward. ${ }^{\ddagger} P$ values are from the Mann-Whitney $U$ test analyzed on nonparametric comparisons between the nurses with (Yes) and without (No) participating in DC. ${ }^{5}$ Others included who graduated a particular course of jnior college or university, five-year school, and graduate course. 
Therefore, the clinical experience was much longer in the Yes group of DC experiences. Sixty-six of all participants $(66 \%)$ were age $<30$. There was a larger proportion of nurses in the No group $51(53.1 \%)$ than in the Yes group 15 $(34.9 \%)$ in the age group $<30$ years. Seventy nurses among the entire group (50.4\%) had a technical college academic background, and there was a larger proportion of nurses in the No group $52(54.2 \%)$ than in the Yes group 18 (41.9\%) in the technical college group. Sixty-nine (49.6\%) nurses had experienced more than 20 postmortem treatments, none said that they had not experienced postmortem treatment. The number distribution of postmortem experiences was as follows: in the Yes group, 10, 4, and 29 nurses in Number of postmortem experiences $1-9,10-19$, and $\geq 20$, respectively; in the No group, 31,25 , and 40 nurses, respectively. There was, therefore, a higher proportion of the number of postmortem experiences $\geq 20$ in the No group $(P<0.01)$. The median (interquartile range) number of DC experiences was 5.5 (2 - 22.5) (Table 2).

No significant differences in characteristics were observed in gender, age, or academic background.

\subsection{In the Univariate Analysis for Items in the Terminal Care Nursing Self-Assessment Sheet by DC Experiences}

In the univariate analysis for items in the Terminal Care, Nursing Self-Assessment Sheet by DC experiences listed in Table 3. Nurses who had experience in DC

Table 3. Univariate analysis for items of terminal care nursing self-assessment sheet by DC experiences.

\begin{tabular}{|c|c|c|c|c|}
\hline & \multirow[b]{2}{*}{ No.* Variables } & \multicolumn{2}{|c|}{ DC experiences } & \multirow{2}{*}{$\begin{array}{c}P \\
\text { value }^{\dagger}\end{array}$} \\
\hline & & $\begin{array}{c}\text { Yes } \\
\mathrm{n}=43\end{array}$ & $\begin{array}{c}\text { No } \\
\mathrm{n}=96\end{array}$ & \\
\hline T1. & I have been able to look back on the nursing I performed. & $3(3-4)$ & $3(2-3)$ & $<0.001$ \\
\hline $\mathrm{T} 2$. & I am strengthening cooperation with other professions about patient care. & $3(3-4)$ & $3(2-3)$ & $<0.001$ \\
\hline T3. & I respect the wishes of patients' family members toward patients. & $4(4-4)$ & $3(3-4)$ & $<0.001$ \\
\hline T4. & I support the decision-making of dying patients and their family. & $4(3-4)$ & $3(2-3)$ & $<0.001$ \\
\hline T5. & I have stress resulting from the patient's inability to relieve mental or physical pain. & $3(3-4)$ & $3(2-3.8)$ & 0.020 \\
\hline T6. & I have stress associated with patients who have a different perception of their conditions. & $3(2-4)$ & $3(2-3)$ & 0.192 \\
\hline T7. & I have stress from patients' emotional expression. & $3(2-4)$ & $2.5(2-3)$ & 0.218 \\
\hline T8. & I am stressed out from responding to questions from patients about life expectancy. & $3(2-4)$ & $2(2-3)$ & 0.019 \\
\hline T9. & I am stressed out by the family of patients who are considered difficult to care for. & $4(2-4)$ & $3(2-4)$ & 0.335 \\
\hline T10. & I have misgivings about procedures and skills for postmortem treatment. & $2(1-3)$ & $2(1-3)$ & 0.916 \\
\hline T11. & I have emotional reactions toward dying patients. & $3(2-4)$ & $2(1-3)$ & 0.036 \\
\hline T12. & I am anxious and worried about the treatment of patients by their families. & $3(2-3)$ & $3(2-3)$ & 0.857 \\
\hline T13. & I feel a renewed bond with my patients and their family. & $4(3-4)$ & $3(2-4)$ & 0.001 \\
\hline & $\begin{array}{l}\text { I have a sense of satisfaction in fulfilling the wishes of the patients, such as the patients } \\
\text { spending time with their families. }\end{array}$ & $3(2.5-4)$ & $2(2-3)$ & $<0.001$ \\
\hline
\end{tabular}

${ }^{*}$ No., Question No., T, Items of Terminal Care Nursing Self-Assessment Sheet. Data are Median (IQR; interquartile range). Variables, Items of Terminal Care Nursing Self-Assessment Sheet. DC, Death Conference, DC experiences were categorized by participating in DC: Yes or No. ${ }^{\dagger} P$ values are from the Mann-Whitney U test analyzed on nonparametric comparisons between the nurses with (Yes group) and without (No group) participating in DC. 
showed significant results (Question No., Category-Items of the Terminal Care Nursing Self-Assessment Sheet) on the following questions. T1. Reflection-having been able to looking back on the nursing care I performed $(P<$ 0.001), T2. Cooperation-strengthening cooperation with other professions about patient care $(P<0.001)$, T13. Cooperation-feeling a renewed bond with my patients and their family $(P=0.001)$, T5. Response to patients-having stress resulting from the patient's inability to relieve mental or physical pain $(P=$ $0.020)$, T8. Response to patients-being stressed out from responding to questions from patients about life expectancy $(P=0.019)$, T3. Response to patients' family - respecting the wishes of patients' family members toward patients $(P<$ $0.001)$, T4. Feelings of the nurse-supporting the decision-making of dying patients and their family $(P<0.001)$, T.11. Feelings of the nurse-having emotional reactions towards dying patients $(P=0.036)$, T14. Feelings of the nursehaving a sense of satisfaction in fulfilling the wishes of the patients, such as the patients spending time with their family $(P<0.001)$.

However, items that did not show a significant relationship with DC experiences were as follows: T6. Response to patients-having stress associated with patients who have a different perception of their conditions $(P=0.192)$, T7. Response to patients-having stress from patients' emotional expression $(P=$ $0.218)$, T9. Response to patients' family-being stressed out by the family of patients who are considered difficult to care for $(P=0.335)$, T12. Response to patients' family-being anxious and worried about the treatment of patients by their families $(P=0.857)$, T10. Specific measures for nursing-have misgivings about procedures and skills for postmortem treatment $(P=0.916)$ (Table 3$)$.

\subsection{Univariate and Multivariate Logistic Regression Analysis for Items of Terminal Care Nursing Self-Assessment Sheet Predicting DC Experiences}

Univariate and multivariate logistic regression analysis for items of the Terminal Care Nursing Self-Assessment Sheet predicting DC experiences are shown in Table 4. In univariate logistic regression analysis, all variables, the original concept, which is the significance of DC included items of the Terminal Care Nursing Self-Assessment Sheet (Refer Table 3), are shown to be independent risk factors for DC experiences as follow (Question No., Category). T1. Reflection (OR 2.43, 95\% CI, 1.52, 3.91, $P<0.001$ ), T2. Cooperation (OR 2.57, 95\% CI, $1.64,4.26, P<0.001$ ), T13. Cooperation (OR 1.85, 95\% CI, 1.25, 2.75, $P=0.001$ ), T5. Response to patients (OR 1.55, 95\% CI, 1.05, 2.35, $P=0.027$ ), T8. Response to patients (OR 1.55, 95\% CI, 1.08, 2.21, $P=0.014$ ), T3. Response to patients' family (OR 2.24, 95\% CI, 1.44, 3.70, $P<0.001$ ), T4. Feelings of the nurse (OR 3.37, 95\% CI, 2.12, 5.73, $P<0.001$ ), T11. Feelings of the nurse (OR 1.50, 95\% CI, $1.07,2.14, P=0.018$ ), and T14. Feelings of the nurse (OR 2.26, 95\% CI, 1.51, $3.55, P<0.001)$.

In model 1 of the multivariate logistic regression analysis adjusted for gender, affiliation (HCU, ER, Palliative Care Ward), clinical experience, age, academic 
Table 4. Univariate and multivariate logistic regression analysis for items of terminal care nursing self-assessment sheet predicting DC experiences.

\begin{tabular}{|c|c|c|c|c|c|c|c|c|c|c|c|c|c|}
\hline \multirow[b]{2}{*}{ Variable } & \multirow[b]{2}{*}{ No. } & \multirow[b]{2}{*}{$\begin{array}{l}\text { Crude } \\
\text { OR }\end{array}$} & \multirow[b]{2}{*}{$95 \% \mathrm{Cl}$} & \multirow[b]{2}{*}{$\begin{array}{c}P \\
\text { Value }\end{array}$} & \multicolumn{3}{|c|}{ Model 1} & \multicolumn{3}{|c|}{ Model 2} & \multicolumn{3}{|c|}{ Model 3} \\
\hline & & & & & $\begin{array}{c}\text { Adjusted } \\
\mathrm{OR}^{*}\end{array}$ & $95 \% \mathrm{Cl}$ & $\begin{array}{c}P \\
\text { Value }\end{array}$ & $\begin{array}{c}\text { Adjusted } \\
\mathrm{OR}^{\dagger}\end{array}$ & $95 \% \mathrm{Cl}$ & $\begin{array}{c}P \\
\text { Value }\end{array}$ & $\begin{array}{c}\text { Adjusted } \\
\mathrm{OR}^{\ddagger}\end{array}$ & $95 \% \mathrm{Cl}$ & $\begin{array}{c}P \\
\text { Value }\end{array}$ \\
\hline \multicolumn{14}{|l|}{ Reflection } \\
\hline $\begin{array}{l}\text { Review of nursing care provided } \\
\text { by self-reflection }\end{array}$ & $\mathrm{T} 1$ & 2.43 & $\begin{array}{l}1.52 \\
3.91\end{array}$ & $<0.001$ & 1.95 & $\begin{array}{l}1.11 \\
3.62\end{array}$ & 0.021 & 2.43 & $\begin{array}{l}1.40 \\
4.23\end{array}$ & $<0.001$ & 2.52 & $\begin{array}{l}1.50 \\
4.23\end{array}$ & $<0.001$ \\
\hline \multicolumn{14}{|l|}{ Cooperation } \\
\hline Collaboration with other professions & $\mathrm{T} 2$ & 2.57 & $\begin{array}{l}1.64 \\
4.26\end{array}$ & $<0.001$ & 1.84 & $\begin{array}{l}1.02 \\
3.51\end{array}$ & 0.042 & 2.46 & $\begin{array}{l}1.41 \\
4.31\end{array}$ & $<0.001$ & 2.71 & $\begin{array}{l}1.60 \\
4.59\end{array}$ & $<0.001$ \\
\hline Bond with patient and family & T13 & 1.85 & $\begin{array}{l}1.25 \\
2.75\end{array}$ & 0.001 & 1.83 & $\begin{array}{l}1.07 \\
3.29\end{array}$ & 0.027 & 2.30 & $\begin{array}{l}1.38 \\
3.85\end{array}$ & $<0.001$ & 2.44 & $\begin{array}{l}1.54 \\
4.09\end{array}$ & $<0.001$ \\
\hline \multicolumn{14}{|l|}{ Response to patients } \\
\hline $\begin{array}{l}\text { Response to unrelieved mental } \\
\text { and physical pain in a patient }\end{array}$ & T5 & 1.55 & $\begin{array}{l}1.05 \\
2.35\end{array}$ & 0.027 & 1.49 & $\begin{array}{l}0.84 \\
2.81\end{array}$ & 0.179 & 1.48 & $\begin{array}{l}0.87 \\
2.52\end{array}$ & 0.140 & 1.57 & $\begin{array}{l}1.00 \\
2.47\end{array}$ & 0.045 \\
\hline $\begin{array}{l}\text { The act of responding to a patient's } \\
\text { emotional expression and questions } \\
\text { about the patient's remaining life }\end{array}$ & T8 & 1.55 & $\begin{array}{l}1.08 \\
2.21\end{array}$ & 0.014 & 1.59 & $\begin{array}{l}0.96 \\
2.63\end{array}$ & 0.069 & 1.62 & $\begin{array}{l}1.04 \\
2.51\end{array}$ & 0.027 & 1.58 & $\begin{array}{l}1.06 \\
2.35\end{array}$ & 0.023 \\
\hline Response to patients' family & & & & & & & & & & & & & \\
\hline Respect for family-to-patient wishes & $\mathrm{T} 3$ & 2.24 & $\begin{array}{l}1.44 \\
3.70\end{array}$ & $<0.001$ & 1.81 & $\begin{array}{l}1.04 \\
3.43\end{array}$ & 0.036 & 2.41 & $\begin{array}{l}1.37 \\
4.25\end{array}$ & $<0.001$ & 2.70 & $\begin{array}{l}1.59 \\
4.60\end{array}$ & $<0.001$ \\
\hline \multicolumn{14}{|l|}{ Feelings of the nurse } \\
\hline $\begin{array}{l}\text { Thoughts of nurses who support } \\
\text { the decision-making of terminal } \\
\text { cancer patients }\end{array}$ & $\mathrm{T} 4$ & 3.37 & $\begin{array}{l}2.12 \\
5.73\end{array}$ & $<0.001$ & 2.76 & $\begin{array}{l}1.48 \\
5.71\end{array}$ & 0.001 & 3.55 & $\begin{array}{l}1.93 \\
6.53\end{array}$ & $<0.001$ & 4.16 & $\begin{array}{l}2.32 \\
7.46\end{array}$ & $<0.001$ \\
\hline $\begin{array}{l}\text { Awareness of the emotional } \\
\text { reaction to a dying patient }\end{array}$ & T11 & 1.50 & $\begin{array}{l}1.07 \\
2.14\end{array}$ & 0.018 & 1.73 & $\begin{array}{l}1.06 \\
2.95\end{array}$ & 0.029 & 1.65 & $\begin{array}{l}1.06 \\
2.56\end{array}$ & 0.022 & 1.58 & $\begin{array}{l}1.07 \\
2.35\end{array}$ & 0.019 \\
\hline $\begin{array}{l}\text { Satisfaction with satisfying } \\
\text { patients' wishes }\end{array}$ & $\mathrm{T} 14$ & 2.26 & $\begin{array}{l}1.51 \\
3.55\end{array}$ & $<0.001$ & 1.42 & $\begin{array}{l}0.79 \\
2.54\end{array}$ & 0.234 & 2.07 & $\begin{array}{l}1.24 \\
3.45\end{array}$ & 0.003 & 2.33 & $\begin{array}{l}1.45 \\
3.73\end{array}$ & $<0.001$ \\
\hline
\end{tabular}

DC, Death Conference, OR, odds ratio. CI, confidence interval. No., question no. Variable, the original concept of items of Terminal Care Nursing Self-Assessment Sheet (Refer Table 2). *Adjusted for gender, affiliation (HCU, ER, Palliative Care Ward), clinical experience, age, academic background, postmortem experience. (Model 1). ${ }^{\dagger}$ Adjusted for gender, affiliation (HCU, others), clinical experience, age, academic background, postmortem experience. (Model 2). ${ }^{\ddagger}$ Adjusted for gender, academic background. (Model3). DC experiences were categorized by participating in DC: Yes or No. OR reviled Yes/No. $P$-Values for the Whole Model Test of all variables predicting DC experience in model 1, model 2, and model 3 are all less than 0.001 , which are by specific likelihood ratio Chi-square tests that evaluate how well the categorical model fits the data.

background, postmortem experience, variables; the original concept, which is the significance of DC of items of the Terminal Care Nursing Self-Assessment Sheet, are shown to be independent risk factors for DC experiences as follows (Question No., Category). T1. Reflection (OR 1.95, 95\% CI, 1.11, 3.62, $P=$ 0.021), T2. Cooperation (OR 1.84, 95\% CI, 1.02, 3.51, $P=0.042$ ), T13. Cooperation (OR 1.83, 95\% CI, 1.07, 3.29, $P=0.027$ ), T3. Response to patients' family (OR 1.81, 95\% CI, 1.04, 3.43, $P=0.036$ ), T4. Feelings of the nurse (OR 2.76, 95\% CI, 1.48, 5.71, $P<0.001$ ), and T11. Feelings of the nurse (OR 1.73, 95\% CI, 1.06, $2.95, P=0.029)$. However, in the following questions of T5, T8, and T14, no sig- 
nificant difference was seen using model 1.

In model 2 of the multivariate logistic regression analysis adjusted for gender, affiliation (HCU, others), clinical experience, age, academic background, postmortem experience, variables; the original concept, which is the significance of DC of items of the Terminal Care Nursing Self-Assessment Sheet, are shown to be independent risk factors for DC experiences as follows (Question No., Category). T1. Reflection (OR 2.43, 95\% CI, 1.40, 4.23, $P<0.001$ ), T2. Cooperation (OR 2.46, 95\% CI, 1.41, 4.31, $P<0.001$ ), T13. Cooperation (OR 2.30, 95\% CI, $1.38,3.85, P<0.001$ ), T8. Response to patients (OR 1.62, 95\% CI, 1.04, 2.51, $P=$ 0.027), T3. Response to patients' family (OR 2.41, 95\% CI, 1.37, 4.25, $P<0.001$ ), T4. Feelings of the nurse (OR 3.55, 95\% CI, 1.93, 6.53, $P<0.001$ ), T11. Feelings of the nurse (OR 1.65, 95\% CI, 1.06, 2.56, $P=0.022$ ), and T14. Feelings of the nurse (OR 2.07, 95\% CI, 1.24, 3.45, $P=0.003$ ). However, in the questions of T5, no significant difference was seen using model 2.

Moreover, in model 3 of the multivariate logistic regression analysis adjusted for gender, academic background, all variables; the original concept, which is the significance of DC of items of the Terminal Care Nursing Self-Assessment Sheet, are shown to be independent risk factors for DC experiences as follows (Question No., Category). T1. Reflection (OR 2.52, 95\% CI, 1.50, 4.23, $P<0.001$ ), T2. Cooperation (OR 2.71, 95\% CI, 1.60, 4.59, $P<0.001$ ), T13. Cooperation (OR 2.44, 95\% CI, 1.54, 4.09, $P<0.001$ ), T5. Response to patients (OR 1.57, 95\% CI, $1.00,2.47, P=0.045$ ), T8. Response to patients (OR 1.58, 95\% CI, 1.06, 2.35, $P=$ 0.023 ), T3. Response to patients' family (OR 2.70, 95\% CI, 1.59, 4.60, $P<0.001$ ), T4. Feelings of the nurse (OR 4.16, 95\% CI, 2.32, 7.46, $P<0.001$ ), T11. Feelings of the nurse (OR 1.58, 95\% CI, 1.07, 2.35, $P=0.019$ ), and T14. Feelings of the nurse (OR 2.33, 95\% CI, 1.45, 3.73, $P<0.001$ ).

\section{Discussion}

\subsection{Nurses' Terminal Care Related to DC Experiences}

Under the hypothesis that DC experience is indispensable for improving the quality of nurses' terminal care and developing nursing minds, we analyzed the relationship with the current situation of nurses' terminal care based on whether or not they have participated in DC. There were significant differences in five categories (Reflection, Cooperation, Response to patients, Response to patients' family, and Feelings of the nurse).

For the assessment items of the categories that were significant in the univariate analysis described above, a significant association with the experience of participating in DC was confirmed by univariate and multivariate logistic regression analysis using adjustment factors. By increasing the number of DC participation, nurses expected to improve the quality of nurse's terminal care and developing nursing minds. Therefore, there is a need for further evidence on the impact of repeated DC experiences on the nurses' terminal care and nursing in DC. 


\subsection{Current Status and Issues of Nurses' Terminal Care that Was Not Related to DC Experiences}

There was no significant association between the experience of participating in DC and the following category (the significance of DC) corresponding to items in the Terminal Care Nursing Self-Assessment Sheet. They are the following category (the significance of DC) that Response to patients (involvement with patients who have a gap in perceptions of the condition, and the act of responding to a patient's emotional expression and questions about patient's remaining life), Response to patients' family (dealing with family members of patients who seems to have difficulty involved, and anxiety and concern about the family's treatment of patients) and Specific measures for nursing (procedures for postmortem treatment and technique concerns).

For the above four items among five, it is necessary to have a time to hold DC regularly and to analyze the content and quality of DC to reduce the stress of nurses performing terminal care even in busy to respond to patients and their families. Nurses' stress has been shown in previous studies. According to a survey using the past CES-D (Depression Evaluation Index), 54.0\% of nurses working in acute wards tend to be depressed, and the intention to leave their jobs tends to be about twice as high when they are depressed than when they are not depressed [19]. The result means that nurses who worked in the acute ward are under stress due to the environment where they were always imposed with a sense of urgency and tension. Knowing the current situation, nurses think that measures are also crucial for mental illness.

In communicating with patients and their families, nurses themselves must improve their work culture and enrich their views of life and death. It stated that more than $90 \%$ of nurses answered that nurses failed to provide needed care for dying patients and families in intensive care [20]. In the case of ER and ICU, there is stress due to a sense of loss for the patient because death has suddenly become imminent in a short time. It is necessary to share the details of correspondence with patients and families with team members and to consider future measures. It was reported in the other previous study using FACT-BJ to evaluate the terminal care attitude of nurses for "dying patients" with a life expectancy of six months or less, that DC reassured nurses of the need to communicate with patients and improved their awareness [21]. It is also necessary to secure time for communication with patients and their families. Therefore, participation in DC is required.

Regarding anxiety about the postmortem treatment of the patient, it is necessary to acquire knowledge and skills through training. In hospitals, it is necessary to examine the contents of nursing standards and procedures related to postmortem treatment, dealing with family members at that time, and regarding DC. According to the free description of the attitude survey on terminal care for 17 nurses in the psychiatric ward due to the introduction of terminal care, sharing of anxiety and doubts about care among staff members has led to increased self-confidence in their own care field [22]. Recognizing the limitations of 
self-care with DC and confirming the care that has been done could lead to confidence [8]. In a questionnaire survey on the view of life and death of nurses who care for the elderly, nurses participating in death conference saw the death significantly positively. Death Conference is a meaningful place to share views of life and death [23]. This time, using the Terminal Care Nursing Self-Assessment Sheet, we conducted a study on the relationship between the presence or absence of participation in DC and the current situation of terminal care for nurses. The terminal care nursing self-evaluation sheet clarified the current situation and future issues of terminal care for improving the quality of terminal care.

This study has several limitations. The generalizability may be limited because the number of participants was small. To generalize these results, we need to add many more participants. The future task is to verify the reliability and validity of the Terminal Care Nursing Self-Assessment Sheet.

\section{Conclusion}

It suggested that DC that looks back on terminal care has significance as an opportunity to consider the way and direction of future care. It is required to raise the quality of DC itself. At DC, it is essential for each nurse to self-assess their nursing and to do a team-based review to enhance each individual's view of nursing. It is a challenge to improve the quality of patient care and promote the mental development of nurses by making improvements in consideration of the reliability and validity of the evaluation indexes to be used at DC.

\section{Conflicts of Interest}

The authors declare no conflicts of interest regarding the publication of this paper.

\section{Funding}

This research did not receive any specific grant from funding agencies in the public, commercial, or not-for-profit sectors.

\section{Authors' Contributors}

Yuko Harding: participated in the conception and design, analysis and interpretation of data, drafting the article, revising it for intellectual content, and final approval of the finished article.

Yoshiko Ishibashi: acquisition of data, final approval of the finished article. Mikiko Mori: acquisition of data, final approval of the finished article.

Masako Yano: participated in the conception and design, interpretation of data, revising it for intellectual content, final approval of the finished article.

Michiyo Ando: revising it for intellectual content, final approval of the finished article.

\section{References}

[1] Komatsu, H., Kojima, M., Iwai K., Tejima, M., Hamaguchi, K. and Kaharu T. (1988) 
A Study on Nurse's Stress Related to End-of-Life Care (1)-Relationship between Stress Factors and Stress State. The 19th Annual Meeting of the Japan Nursing Association (Nursing Management), Osaka, 6-7 December 1988, 243-246.

https://ci.nii.ac.jp/naid/50002661277/en/?range $=0 \&$ sortorder $=1 \&$ start $=1 \&$ count $=20$ \&q

[2] Kawano, H. (1988) Aid for Death Anxiety. The Japanese Journal of Clinical Nursing Monthly, 14, 812-816.

https://ci.nii.ac.jp/naid/50002740589/en/?range=0\&sortorder $=1 \&$ start $=1 \&$ count $=20$ \&q

[3] Kimoto, Y. and Kuraishi, T. (2003) Nurse's Consciousness in Emergency Room Terminal Care. Hospice and Home Care, 11, 309-313. https://jglobal.jst.go.jp/en/detail?JGLOBAL_ID=200902205420419573

[4] Okamoto, F. and Ishii, K. (2005) Development for a Nurse's View of Life-and-Death Scale and Analysis of Its Influencing Factors. Journal of Japan Society of Nursing Research, 28, 53-60.

https://www.jstage.jst.go.jp/article/jjsnr/28/4/28_20050524005/_article/-char/en

[5] Kashiwagi, T. (2007) Life and Death (1) Medicine Various Words about End-of-Life Care. Clinic All-Round, 56, 2744-2748. https://ci.nii.ac.jp/naid/40015621486

[6] Asami, A. (2013) The Relationship between End-of-Life Care and Nurses' Awareness of End-of-Life Care in the ICU. Journal of Japan Academy of Critical Care Nursing, 9, 39-47.

https://jglobal.jst.go.jp/en/detail?JGLOBAL_ID=201302279493360590\&rel

[7] End-of-Life Nursing Practice Guide in Emergency and Intensive Care Units. http://jaen.umin.ac.jp/EOL_guide.html

[8] Hirose, H. (2011) Grief Care for Family and Nurses. Igaku-Shoin Ltd., Tokyo. https://iss.ndl.go.jp/books/R100000002-I000011224361-00

[9] Hasebe, M., Taguchi, M. and Tsuge, M. (2012) Effect of Death Conferences as Seen from Changes in Nurses' Comments. Nihon Kango Gakkai Rombunshuu, Kango Sougou, 42, 218-221. https://iss.ndl.go.jp/books/R000000004-I023617204-00

[10] Naito, C., Nakai, O., Omote, S., Yabuta, Y., Hoshino, T. and Miyahata, T. (2009) The Effect of Death Conferences in Terminal Care; Evaluation of Stress Reduction Using POMS. Nihon Kango Gakkai Rombunshuu, Kango Kanri, 39, 330-332. https://jglobal.jst.go.jp/en/detail?JGLOBAL_ID=200902260488192837

[11] Hasegawa, M., Eto, A. and Yamauchi, N. (2007) Impact of Death Conference in the Medical Team on Nurses' Self-Efficacy. Nihon Kango Gakkai Rombunshuu, Kango Sougou, 38, 49-51. https://jglobal.jst.go.jp/en/detail?JGLOBAL_ID=200902285011484057

[12] Kobayashi, M. and Shibuya, M. (2010) Consideration of Terminal Care in Our Hospital Ward. By Introducing Death Conferences. Pre-Symptomatic Medicine and Anti Aging, 19, 143-145. https://jglobal.jst.go.jp/en/detail?JGLOBAL_ID=201002214228207333

[13] Harding, Y., Ando, M. and Yano, M. (2019) Literature Review on the Significance of Death Conferences for Nurses in Japan. Open Journal of Nursing, 9, 521-533. https://www.scirp.org/journal/paperinformation.aspx?paperid=92618 https://doi.org/10.4236/ojn.2019.95044

[14] Tanaka, H., Moriya, A. and Sakiko, K. (2014) The Thoughts of a Nurse Supporting an End-Term Cancer Patient's Decision-Making: Nursing Which Builds Close Relationships to the Patient Family Who Passes the Time of the Last Moment Is Considered. Annals of Nursing Research, Shinshu University Hospital, 42, 38-40. 
https://ci.nii.ac.jp/naid/40020282208

[15] Adachi, K. and Tashiro, M. (2012) Deployment of Death Conferences and Nurse's Mind. From a Survey of Nurses for the Introduction. The Japanese Psychiatric Nursing Association, 55, 550-551. https://jglobal.jst.go.jp/en/detail?JGLOBAL_ID=201202226647441608

[16] Koyama, K., Kazama, K., Nakamura, M., Aonuma, E. and Yoshikawa, K. (2012) Behavioral Change of Staff by Death Conferences in Acute Care Ward-Aiming at Improvement of Quality of Terminal Care. Nagano-Prefecture Kango Kenkyuu Gakkai Rombunshuu, 32, 79-81. https://jglobal.jst.go.jp/en/detail?JGLOBAL_ID=201202259594399200

[17] Ishikawa, C. and Hashizume, T. (2010) Nurse's Stress in Palliative Care Seen from Death Conferences. The Medical Journal of Akita City Hospital, 19, 1-5. https://jglobal.jst.go.jp/en/detail?JGLOBAL_ID=201002226948889952

[18] Tsuchie, K., Sasaki, M., Kumagai, N. and Ishibashi, T. (2010) Analysis of Way of Grasping Death Conferences by Nurses in Chronic Medical Ward and Consideration of Effective Progress. Nihon Kango Gakkai Rombunshuu, Kango Sougou, 40, 425-427. https://jglobal.jst.go.jp/en/detail?JGLOBAL_ID=201002206420128002

[19] Kaneko, S. (2014) The Relationship between the Depressive Tendency, Medical Safety, and Intention to Leave for Nurses Working in Acute Wards. Bulletin of Nagoya City University School of Nursing, 13, 19-25. https://jglobal.jst.go.jp/en/detail?JGLOBAL_ID=201402224341928637\&rel

[20] Murase, M. (2001) Examination of Terminal Care in Intensive Care Area-Attitude Survey of Nurses Working in the Field. 32nd Nihon Kango Gakkai Rombunshuu, seijin Kango, Vol. 1, 78-80. https://jglobal.jst.go.jp/en/detail?JGLOBAL_ID=200902128829679874

[21] Aoshima, H., Ishikura, S., Furihata, K. and Kaneko, K. (2014) The Effect of Mobility and Mortality Conference: Based on Assessment of the Nurse Attitude for Terminal Care Using FATCOD-B-J. Annals of Nursing Research, Shinshu University Hospital, 42, 30-34.

https://ci.nii.ac.jp/naid/120005526764/en/?range $=0$ \&sortorder $=0 \&$ start $=0 \&$ count $=0$

[22] Onuki, Y., Shigenaga, T., Eguchi, S., Nakayama, S. and Saito, K. (2015) Introduction of Death Conference and Its Effects Initiatives for Terminal Care. The Japanese Psychiatric Nursing Society, 58, 214-218.

http://mol.medicalonline.jp/library/journal/abstract?GoodsID=ap0sejui/2015/00580 $\underline{3 / 043 \& \text { name }=0214-0218 \mathrm{j} \& \text { UserID }=110.54 .110 .169}$

[23] Kurashiki, K. (2014) Examination of the View of Life and Death of Nurses and Care Staff Involved in Elderly Care. Nihon Kango Gakkai Rombunshuu, Kango Sougou, 44, 185-188. https://ci.nii.ac.jp/naid/40020033610 